\title{
Epithelioid Trophoblastic Tumor
}

National Cancer Institute

\section{Source}

National Cancer Institute. Epithelioid Trophoblastic Tumor. NCI Thesaurus. Code C6900.

A gestational trophoblastic tumor characterized by the presence of a monomorphous cellular population of intermediate trophoblastic cells infiltrating in a nodular pattern. 